\title{
Perbandingan Hasil Koreksi Mata Sipit Menggunakan Dua Bulu Mata dengan Penambahan Scotch Tape dan Tiga Bulu Mata untuk Rias Pengantin Bridal
}

\author{
Khumairah \\ Pendidikan Tata Rias Dan Kecantikan, Fakultas Pariwisata Dan Perhotelan, Universitas Negeri Padang \\ e-mail : khumairahsulbis90@gmail.com \\ Murni Astuti \\ Pendidikan Tata Rias Dan Kecantikan, Fakultas Pariwisata Dan Perhotelan, Universitas Negeri Padang \\ e-mail : murni.astuti937@gmail.com
}

\begin{abstract}
The purpose of the research to knows comparison of slit eye correction results using two lashes with the addition of scotch tape and three lashes for bridal makeup. This research method uses quasi-experimental methods with Non equivalent control group design. Sampling using purposive sampling technique. The analysis shows that there are differences in the level of neatness in the technique of using two lashes with scotch tape and the use of three lashes for bridal makeup $(p=0,035)$. Where the highest average value was found using three Eyelashes (X2) which is equal to 2.47. There are no significant differences in eye impression indicators seen in the technique of using two lashes with scotch tape and the use of three lashes for bridal makeup $(p=0,035)$. However, the highest average value was found using three Eyelashes (X2) which was equal to 2.67. There are significant differences in eye impression indicators on the technique of using two lashes with the addition of scotch tape and the use of three lashes for bridal makeup ( $p=0,010)$. Where the highest average value was found using three Eyelashes (X2) which is equal to 2.93. the best result bridal makeup is using three eyelashes technique for more perfect .
\end{abstract}

Keywords: Bridal Makeup, Slit Eyes, False Eyelashes, Scotch Tape

\section{PENDAHULUAN}

Wanita dan kecantikan adalah dua hal yang bagi banyak orang sulit dipisahkan. Tuntutan untuk selalu tampil cantik akan selalu mengikuti sosok wanita kemana pun ia pergi, dimana pun ia berada, dan pada usia mana pun. Wanita selalu ingin terlihat cantik di dalam berbagai kesempatan, Banyak cara yang dilakukan agar mereka terlihat cantik mulai dari hal yang sederhana seperti merias wajah untuk kepentingan sehari-hari sampai melakukan bedah plastik hanya karena ingin terlihat cantik di berbagai kesempatan. Hal yang paling utama dilakukan oleh seorang wanita agar terlihat cantik adalah dengan cara merias wajah sebelum melakukan aktifitas.
Rias wajah atau dapat disebut dengan istilah makeup merupakan suatu seni wajah yang bertujuan untuk memperindah dan mempercantik penampilan wajah, dengan teknik make up yang benar akan dapat menutupi beberapa kekurangan pada wajah, membuat penampilan wajah terlihat fresh (Kusantati, 2008:452). Istilah makeup lebih sering di tujukan kepada pengubahan bentuk wajah atau korektif wajah yaitu mengubah bentuk asli sebenarnya dengan menggunakan bantuan bahan dan alat kosmetik.

Rias wajah korektif selalu berhubungan dengan penampilan natural dan sederhana namun lebih elegan karena dapat mengkoreksi kekurangan dan kelebihan di wajah agar terlihat lebih segar. Untuk menutupi kekurangan dan menonjolkan kelebihan seseorang dalam rias wajah maka rias wajah koreksi adalah hal yang harus 
Dilakukan, Oleh karena itu, Tata rias korektif sangat berguna dalam tata rias pengantin barat.

Pada rias pengantin barat biasanya pengantin mengenakan gaun putih karena mengandung arti kesucian, serta memberi nuansa lembut. Sehingga rias pengantin internasional biasanya menggunakan warna warna yang

natural, memakai foundation yang ringan, memakai eyeshadow yang tidak mengkilap, rouge dan lipstik yang tidak menyala/ warna-warna pastel (Gusnaldi, 2008:104).

Mata yang sempurna memiliki bentuk mata yang seimbang, besar dan berkelopak indah, pada kenyataannya tidak semua wanita yang dilahirkan dengan bentuk mata

yg ideal. Diantara bentuk mata yang kurang ideal itu adalah mata dekat, mata berjauhan, mata dalam atau mata cekung, mata turun, mata berkantong, mata bengkak, mata sipit, mata besar (han, 2010:59)

Belum sempurnanya riasan wajah, maka tidak akan lengkap dengan riasan mata yang tepat sesuai koreksinya. Riasan mata merupakan bagian terpenting dalam menampilkan keseluruhan riasan wajah, ketika bentuk mata yang tidak sempurna di sulap sedemikian rupa dengan bantuan kosmetik dan bulu mata maka tampilan keseluruhan wajah pun berubah seketika (Liza, 2017:6). Menyikapi pendapat tersebut bahwasanya riasan mata merupakan bagian terpenting dalam menampilkan keseluruhan riasan wajah. Jadi, untuk mencapai bentuk mendekati ideal maka mata yang memiliki bentuk beragam dapat diubah menggunakan teknik koreksi. Salah satu tekniknya adalah menggunakan dua bulu mata palsu ditambah dengan scotch tape dan tiga bulu mata palsu.

Bulu mata palsu merupakan bulu mata tiruan dari bahan sintetis yang memberikan efek tebal atau memunculkan efek-efek tertentu pada wajah, termasuk mengoreksi kekurangan pada mata, sedangkan scotch tape adalah kertas kertas khusus yang mampu menerima warna kosmetik mata yang diaplikasikan diatasnya. Scotch tape berfungsi sebagai pengganjal kelopak mata untuk membentuk mata agar terbentuk dan terlihat lebih lebar (Andiyanto, 2005:34).

Dalam tata rias pengantin bridal tidak semua wanita yang mempunyai mata ideal, Dari beberapa bentuk mata yang ada salah satu bentuk mata yang kurang ideal dan membutuhkan konsentrasi tersendiri dalam mengoreksinya adalah mata sipit. Bentuk mata sipit adalah salah satu bentuk mata yang banyak ditemui pada masyarakat Indonesia terutama orang cina. Karena mata sipit identik dengan Etnis Cina atau yang lebih sering disebut etnis Tionghoa.

Untuk mencapai bentuk mata mendekati ideal maka mata sipit dapat menggunakan teknik koreksi yaitu menggunakan bulu mata palsu dan scotch tape. Pemasangan beberapa bulu mata palsu dan scotch tape untuk koreksi mata sipit dalam tata rias pengantin bridal berguna untuk membuat mata mendekati ideal sehingga terlihat terbuka, tajam, indah dan segar. Jenis bulu mata yang tepat digunakan untuk mengoreksi mata sipit yang pertama adalah bulu mata bulat dengan ciri-ciri yaitu, memiliki helaian yang lebih panjang dan jarak antar helaian yang rapat, sehingga membuat mata tampak lebih bulat dan bersinar. Yang kedua adalah bulu mata panjang dengan ciri-ciri mempunyai helaian yang lebih panjang dan tebal, sehingga membuat sudut luar mata terkesan lebih panjang dan naik (Gusnaldi, 2010:31).

Penelitian ini dimaksudkan untuk membuat mata yang sipit mendekati ideal dengan membandingkan penggunaan tiga lapis bulu mata palsu dengan bentuk yang berbeda sesuai dengan koreksi mata sipit dan penggunaan scoth tape ditambah dengan dua lapis bulu mata untuk tata rias pengantin bridal.

Berdasarkan pengalaman pribadi yang penulis lakukan di lapangan tanggal 8 dan 15 Juli 2017, banyak penata rias (MUA) baru di kota Padang yang kesulitan dalam melakukan koreksi mata sipit ini, kesulitannya yaitu dalam teknik pemasangan scoth tape dan pemilihan jenis bulu mata yang digunakan mengakibatkan mata model semakin kecil dan terkesan berat. Serta 3 dari 5 penata rias (MUA) tersebut hanya mengandalkan teknik cut crease eyeshadow dalam mengoreksi mata sipit. Oleh karena itu koreksi mata sipit membutuhkan kemampuan untuk melakukan teknik tepat dalam melakukannya. Berdasarkan permasalahan tersebut penulis memilih

bentuk mata sipit sebagai objek penelitian ini dengan judul "Perbandingan Hasil Koreksi Mata Sipit Menggunakan dua Bulu Mata Dengan Penambahan Scotch Tape Dan tiga Bulu Mata Untuk Tata Rias Pengantin Bridal”.

\section{METODE}

Penelitian ini adalah eksperimen semu (quasi eksperimen). Dengan desain penelitian Nonequivalent Control Group Design. Dengan desain penelitian sebagai berikut:

Gambar 1 : Desain Penelitian Perbandingan Hasil Koreksi Mata Sipit Menggunakan Dua Bulu Mata Ditambah Dengan Scotch Tape Dan Tiga Bulu Mata Untuk Rias Pengantin Bridal. 


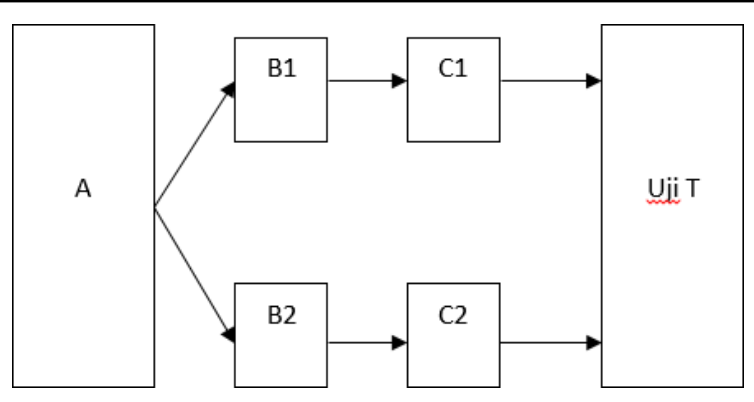

Keterangan :

A : Jumlah sampel keseluruhan (wanita chinese bermata sipit)

B1 : Pelaksanaan rias pengantin bridal untuk mengoreksi mata sipit dengan menggunakan scotch tape dan dua lapis bulu mata

B2 : Pelaksanaan rias pengantin bridal untuk mengoreksi mata sipit dengan menggunakan tiga lapis bulu mata

C1 : Hasil pelaksanaan rias pengantin bridal untuk mengoreksi mata sipit dengan menggunakan scotch tape dan dua lapis bulu mata

C2 : Hasil pelaksanaan rias pengantin bridal untuk mengoreksi mata sipit dengan tiga lapis bulu mata

Uji $\mathrm{T}$ : Hasil penelitian dinilai perbandingan yang didapat.

Tempat dan waktu penelitian dilakukan di Workshop Program Studi Pendidikan Tata Rias dan Kecantikan, Fakultas Pariwisata dan Perhotelan, Universitas Negeri Padang pada Bulan Agustus 2018. Populasi dalam penelitian ini adalah wanita chinese yang memiliki mata sipit berusia 19-28 tahun. Pengambilan sampel dengan teknik purposive sampling sebanyak 3 orang wanita chinese. Teknik analisis data menggunakan uji beda t-test. Kriteria pengujian berdasarkan signifikansi dapat dilihat jika presentase $<0,05$, maka hipotesis diterima, tetapi jika $>0,05$ maka hipotesis ditolak. Adapun rumus yang digunakan adala sebagai berikut:

$$
t=\frac{\bar{D}}{S s}
$$

Keterangan:

$\bar{D}$ : Rata-rata yang dipengaruhi kedua pasangan Ss : simpngan baku dipengaruhi kedua pasangan

\section{$t$ : nilai t hitung}

\section{HASIL DAN PEMBAHASAN}

\section{A. Hasil Penelitian}

1. Distribusi Rata-Rata Hasil Koreksi Mata Sipit Dengan Penggunaan dua Bulu Mata Dengan Penambahan Scotch Tape Untuk Tata Rias Pengantin Bridal

Berikut Adalah Tabel 1 Distribusi Rata - Rata Hasil Koreksi Mata Sipit Dengan Penggunaan dua Bulu Mata Dengan Penambahan Scotch Tape Dan tiga Bulu Mata Palsu Untuk Tata Rias Pengantin Bridal

\begin{tabular}{|c|c|c|c|c|c|c|}
\hline $\begin{array}{l}\text { Indikator } \\
\text { Penilaian }\end{array}$ & $\begin{array}{l}\text { Hasil } \\
\text { Ukur }\end{array}$ & Mean & SD & $\operatorname{Min}$ & Maks & $\mathrm{N}$ \\
\hline \multirow[t]{2}{*}{ Kerapian } & $\mathrm{X} 1$ & 1.86 & 0.462 & 1.60 & 2.40 & \multirow{2}{*}{3} \\
\hline & $\mathrm{X} 2$ & 2.47 & 0.503 & 2.00 & 3.00 & \\
\hline \multirow{2}{*}{$\begin{array}{l}\text { Kesan Mata } \\
\text { Terlihat }\end{array}$} & $\mathrm{X} 1$ & 2.33 & 0.611 & 1.80 & 3.00 & \multirow[b]{2}{*}{3} \\
\hline & $\mathrm{X} 2$ & 2.67 & 0.115 & 2.60 & 2.80 & \\
\hline \multirow{2}{*}{$\begin{array}{l}\text { Ukuran } \\
\text { Mata }\end{array}$} & $\mathrm{X} 1$ & 1.60 & 0.200 & 1.40 & 1.80 & \multirow{2}{*}{3} \\
\hline & $\mathrm{X} 2$ & 2.93 & 0.115 & 2.80 & 3.00 & \\
\hline
\end{tabular}

Tabel 1 menggambarkan nilai rata-rata pada indikator kerapian pada hasil pada teknik penggunaan dua bulu mata dengan penambahan scotch tape (X1) adalah sebesar 1.86 dengan standar deviasi \pm 0.462 , nilai minimum 1.60 dan nilai maksimum 2.40. Pada teknik menggunakan tiga bulu mata palsu (X2) adalah sebesar 3.40 dengan standar deviasi \pm 0.503 , nilai minimum 2.00 dan nilai maksimum 3.00.

Nilai rata-rata pada indikator kesan mata terlihat pada teknik penggunaan dua bulu mata dengan penambahan scotch tape (X1) adalah sebesar 2.33 dengan standar deviasi \pm 0.611 , nilai minimum 1.80 dan nilai maksimum 3.00. Pada teknik menggunakan tiga bulu mata palsu (X2) adalah sebesar 2.67 dengan standar deviasi \pm 0.115 , nilai minimum 2.60 dan nilai maksimum 2.80 .

Nilai rata-rata pada indikator ukuran mata pada teknik penggunaan dua bulu mata dengan penambahan scotch tape (X1) adalah sebesar 1.60 dengan standar deviasi \pm 0.200 , nilai minimum 1.40 dan nilai maksimum 1.80. Pada teknik menggunakan tiga bulu mata palsu (X2) adalah sebesar 2.93 dengan standar deviasi \pm 0.115 , nilai minimum 2.80 dan nilai maksimum 3.00 . 
a. Distribusi Frekuensi Kerapian Pada Penggunaan dua Bulu Mata Dengan Penambahan Scotch Tape Untuk Tata Rias Pengantin Bridal

Berikut Adalah Tabel 2 Distribusi Frekuensi Kerapian Pada Penggunaan dua Bulu Mata Dengan Penambahan Scotch Tape Untuk Tata Rias Pengantin Bridal

\begin{tabular}{|c|l|c|c|c|c|c|c|}
\hline Skor & \multirow{2}{*}{ Kategori } & \multicolumn{2}{|c|}{ Objek I } & \multicolumn{2}{|c|}{ Objek II } & \multicolumn{2}{c|}{ Objek III } \\
\cline { 3 - 8 } & & f & $\%$ & F & $\%$ & f & $\%$ \\
\hline 3 & Sangat rapi & 0 & 0.0 & 0 & 0.0 & 2 & 40.0 \\
\hline 2 & Rapi & 3 & 60.0 & 3 & 60.0 & 3 & 60.0 \\
\hline 1 & Tidak rapi & 2 & 40.0 & 2 & 40.0 & 0 & 0.0 \\
\hline & Jumlah & 5 & 100.0 & 5 & $\begin{array}{c}100 . \\
0\end{array}$ & 5 & 100.0 \\
\hline
\end{tabular}

Tabel 2 menunjukkan bahwa distribusi frekuensi kerapian pada penggunaan dua bulu mata dengan penambahan scotch tape (X1) untuk tata rias pengantin bridal dari penilaian 5 panelis terhadap objek 1 dan 2 didapatkan sebanyak 3 orang $(60.0 \%)$ panelis menilai objek pada kategori rapi dan sebanyak 2 orang $(40.0 \%)$ panelis menilai pada kategori tidak rapi. Terhadap objek 3 didapatkan sebanyak 2 orang (40.0\%) panelis menilai pada kategori sangat rapi dan sebanyak 3 orang $(60.0 \%)$ panelis menilai pada kategori rapi.

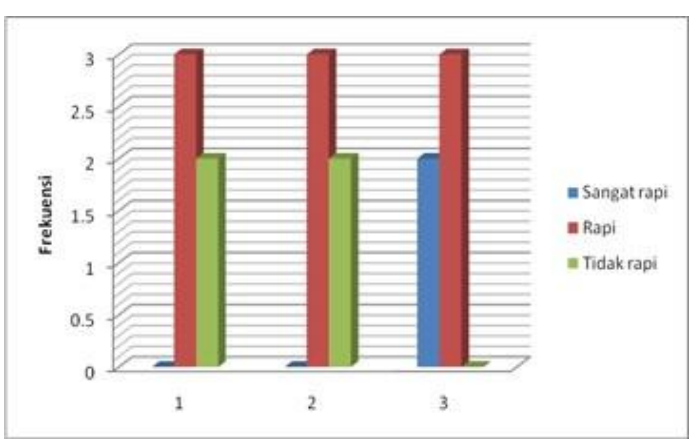

Gambar 1. Histogram Distribusi Frekuensi Kerapian Pada Penggunaan dua Bulu Mata Dengan Penambahan Scotch Tape Untuk Rias Pengantin Bridal (X1). b. Distribusi Frekuensi Kesan mata terlihat Pada Penggunaan dua Bulu Mata Dengan Penambahan Scotch Tape Untuk Tata Rias Pengantin Bridal

Berikut Adalah Tabel 3 Distribusi Frekuensi Kesan Mata terlihat Pada Penggunaan dua Bulu Mata Dengan Penambahan Scotch Tape Untuk Tata Rias Pengantin Bridal

\begin{tabular}{|c|l|c|c|c|c|c|c|}
\hline Skor & \multirow{2}{*}{ Kategori } & \multicolumn{2}{|c|}{ Objek I } & \multicolumn{2}{c|}{ Objek II } & \multicolumn{2}{c|}{ Objek III } \\
\cline { 3 - 8 } & & f & $\%$ & f & $\%$ & f & $\%$ \\
\hline 3 & Ideal & 1 & 20.0 & 0 & 0.0 & 5 & 100.0 \\
\hline 2 & Tetap & 4 & 80.0 & 3 & 60.0 & 0 & 0.0 \\
\hline 1 & $\begin{array}{l}\text { Kurang } \\
\text { ideal }\end{array}$ & 0 & 0.0 & 2 & 40.0 & 0 & 0.0 \\
\hline & Jumlah & 5 & $\begin{array}{c}100 . \\
0\end{array}$ & 5 & $\begin{array}{c}100 \\
0\end{array}$ & 5 & 100.0 \\
\hline
\end{tabular}

Tabel 3 menunjukkan bahwa distribusi frekuensi kesan mata pada penggunaan dua bulu mata dengan penambahan scotch tape (X1) untuk tata rias pengantin bridal dari penilaian 5 panelis terhadap objek 1 didapatkan sebanyak 1 orang (20.0\%) panelis menilai objek pada kategori ideal dan sebanyak 4 orang $(80.0 \%)$ panelis menilai pada kategori tetap. Terhadap objek 2 didapatkan sebanyak 3 orang $(60.0 \%)$ panelis menilai pada kategori tetap dan sebanyak 2 orang $(40.0 \%)$ panelis menilai pada kategori kurang ideal. Terhadap objek 3 didapatkan sebanyak 5 orang $(100.0 \%)$ panelis menilai pada kategori ideal.

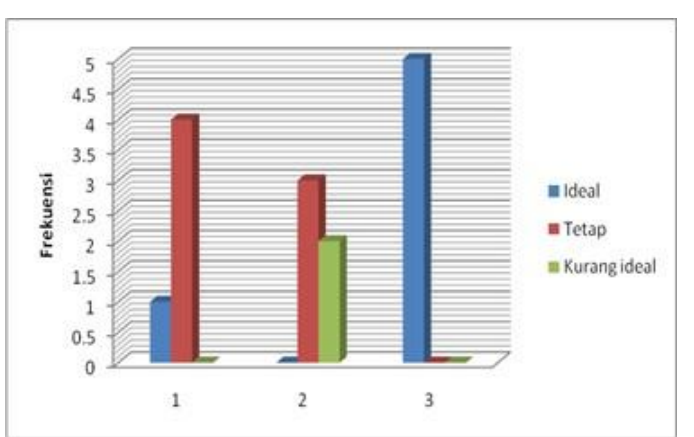

Gambar 2. Histogram Distribusi Frekuensi Kesan Mata Terlihat Pada Penggunaan dua Bulu Mata Dengan Penambahan Scotch Tape Untuk Rias Pengantin Bridal (X1) 
c. Distribusi Frekuensi kesan Ukuran Mata Pada Penggunaan dua Bulu Mata Dengan Penambahan Scotch Tape dan Bulu Mata Untuk Tata Rias Pengantin Bridal

Berikut Adalah Tabel 4 Distribusi Frekuensi kesan Ukuran Mata Pada Penggunaan dua Bulu Mata Dengan Penambahan Scotch Tape Untuk Tata Rias Pengantin Bridal

\begin{tabular}{|c|l|c|c|c|c|c|c|}
\hline Skor & \multirow{2}{*}{ Kategori } & \multicolumn{2}{|c|}{ Objek I } & \multicolumn{2}{|c|}{ Objek II } & \multicolumn{2}{|c|}{ Objek III } \\
\cline { 3 - 8 } & & $\mathbf{f}$ & $\mathbf{\%}$ & $\mathbf{f}$ & $\mathbf{\%}$ & $\mathbf{f}$ & $\%$ \\
\hline 3 & Besar & 0 & 0.0 & 0 & 0.0 & 4 & 80.0 \\
\hline 2 & Tetap & 2 & 40.0 & 5 & $\begin{array}{c}100 \\
0\end{array}$ & 1 & 20.0 \\
\hline 1 & Kecil & 3 & 60.0 & 0 & 0.0 & 0 & 0.0 \\
\hline & Jumlah & 5 & 100.0 & 5 & $\begin{array}{c}100 \\
0\end{array}$ & 5 & 100.0 \\
\hline
\end{tabular}

Tabel 4 menunjukkan bahwa distribusi frekuensi ukuran mata pada penggunaan dua bulu mata dengan penambahan scotch tape (X1) untuk tata rias pengantin bridal dari penilaian 5 panelis terhadap objek 1 didapatkan sebanyak 2 orang $(40.0 \%)$ panelis menilai objek pada kategori besar dan sebanyak 3 orang $(60.0 \%)$ panelis menilai pada kategori tetap. Terhadap objek 2 didapatkan sebanyak 5 orang (100.0\%) panelis menilai pada kategori tetap. Terhadap objek 3 didapatkan sebanyak 4 orang $(80.0 \%)$ panelis menilai pada kategori ideal dan sebanyak 1 orang $(20.0 \%)$ panelis menilai pada kategori tetap.

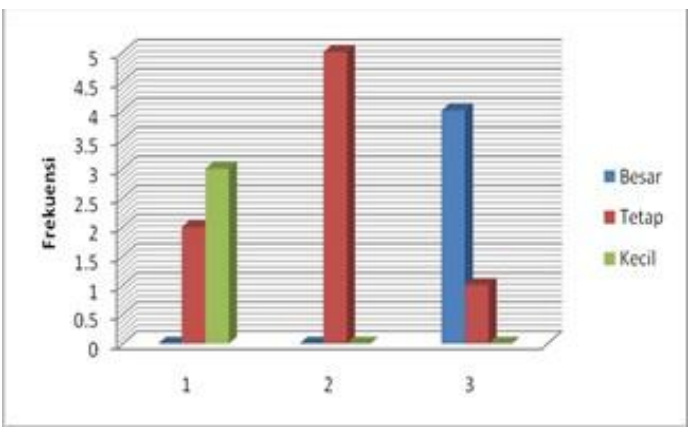

Gambar 3. Histogram Distribusi Frekuensi Ukuran Mata Pada Penggunaan dua Bulu Mata Dengan Penambahan Scotch Tape Untuk Rias Pengantin Bridal (X1).
2. Distribusi Rata-Rata Hasil Koreksi Mata Sipit Dengan Penggunaan tiga Bulu Mata Palsu Untuk Tata Rias Pengantin Bridal

a. Distribusi Frekuensi Kerapian Pada Penggunaan tiga Bulu Mata Untuk Tata Rias Pengantin Bridal

Berikut Adalah Tabel 5 Distribusi Frekuensi Kerapian Pada Penggunaan tiga Bulu Mata Untuk Tata Rias Pengantin Bridal

\begin{tabular}{|c|c|c|c|c|c|c|c|}
\hline \multirow[t]{2}{*}{ Skor } & \multirow[t]{2}{*}{ Kategori } & \multicolumn{2}{|c|}{ Objek I } & \multicolumn{2}{|c|}{ Objek II } & \multicolumn{2}{|c|}{ Objek III } \\
\hline & & f & $\%$ & f & $\%$ & $\mathrm{f}$ & $\%$ \\
\hline 3 & Sangat rapi & 0 & 0.0 & 2 & 40.0 & 1 & 20.0 \\
\hline 2 & Rapi & 5 & 100.0 & 3 & 60.0 & 4 & 80.0 \\
\hline 1 & Tidak rapi & 0 & 0.0 & 0 & 0.0 & 0 & 0.0 \\
\hline & Jumlah & 5 & 100.0 & 5 & $\begin{array}{c}100 . \\
0\end{array}$ & 5 & 100.0 \\
\hline
\end{tabular}

Tabel 5 menunjukkan bahwa distribusi frekuensi kerapian pada penggunaan tiga bulu mata palsu (X2) untuk tata rias pengantin bridal dari penilaian 5 panelis terhadap objek 1 didapatkan sebanyak 5 orang $(100.0 \%)$ panelis menilai objek pada kategori rapi. Terhadap objek 2 didapatkan sebanyak 2 orang $(40.0 \%)$ panelis menilai pada kategori sangat rapi dan sebanyak 3 orang $(60.0 \%)$ panelis menilai pada kategori rapi. Terhadap objek 3 didapatkan sebanyak 1 orang $(20.0 \%)$ panelis menilai pada kategori rapi dan sebanyak 4 orang $(80.0 \%)$ panelis menilai pada kategori rapi.

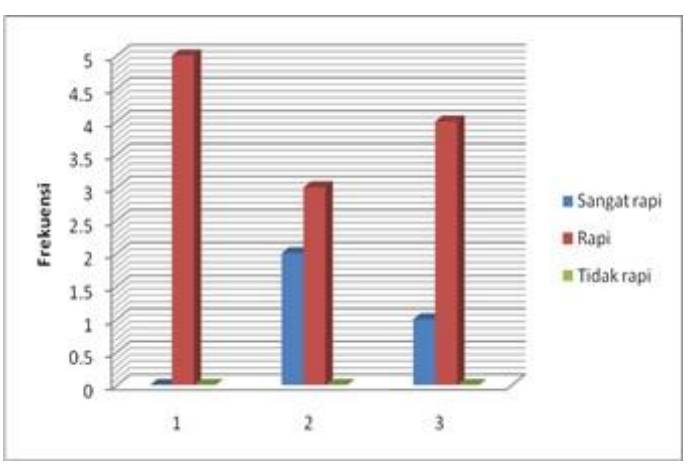

Gambar 4. Histogram Distribusi Frekuensi kerapian hasil koreksi Mata Sipit Pada Penggunaan tiga Bulu Mata Untuk Rias Pengantin Bridal (X2). 
b. Distribusi Frekuensi Kesan mata terlihat Pada Penggunaan tiga Bulu Mata Untuk Tata Rias Pengantin Bridal

Berikut Adalah Tabel 6 Distribusi Frekuensi Kesan Mata Pada Penggunaan tiga Bulu Mata Untuk Tata Rias Pengantin Bridal

\begin{tabular}{|c|l|c|c|c|c|c|c|}
\hline Skor & \multirow{2}{*}{ Kategori } & \multicolumn{2}{|c|}{ Objek I } & \multicolumn{2}{c|}{ Objek II } & \multicolumn{2}{c|}{ Objek III } \\
\cline { 3 - 8 } & & f & $\%$ & f & $\%$ & F & $\%$ \\
\hline 3 & Ideal & 3 & 60.0 & 3 & 60.0 & 4 & 80.0 \\
\hline 2 & Tetap & 2 & 40.0 & 2 & 40.0 & 1 & 20.0 \\
\hline 1 & $\begin{array}{l}\text { Kurang } \\
\text { ideal }\end{array}$ & 0 & 0.0 & 0 & 0.0 & 0 & 0.0 \\
\hline & Jumlah & 5 & 100.0 & 5 & $\begin{array}{c}100 \\
0\end{array}$ & 5 & 100.0 \\
\hline
\end{tabular}

Tabel 6 menunjukkan bahwa distribusi frekuensi kesan mata terlihat pada penggunaan tiga bulu mata (X2) untuk tata rias pengantin bridal dari penilaian 5 panelis terhadap objek 1 dan 2 didapatkan 3 orang $(60.0 \%)$ panelis menilai objek pada kategori ideal dan sebanyak 2 orang $(40.0 \%)$ panelis menilai pada kategori tetap. Terhadap objek 3 didapatkan sebanyak 4 orang $(80.0 \%)$ panelis menilai pada kategori ideal dan sebanyak 1 orang (20.0\%) panelis menilai pada kategori tetap.

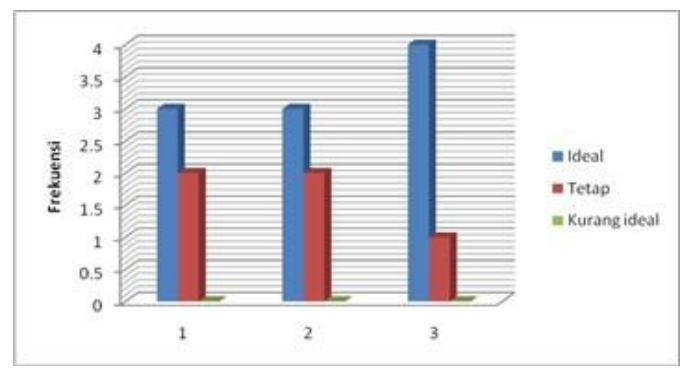

Gambar 5. Histogram Distribusi Frekuensi Kesan Mata terlihat Pada Penggunaan tiga Bulu Mata Untuk Rias Pengantin Bridal (X2)

c. Distribusi Frekuensi kesan Ukuran Mata Pada Penggunaan tiga Bulu Mata palsu Untuk Tata Rias Pengantin Bridal.

Berikut Adalah Tabel 7 Distribusi Frekuensi Ukuran Mata Pada Penggunaan tiga Bulu Mata Untuk Tata Rias Pengantin Bridal

\begin{tabular}{|c|l|c|c|c|c|c|c|}
\hline Skor & \multirow{2}{*}{ Kategori } & \multicolumn{2}{|c|}{ Objek I } & \multicolumn{2}{|c|}{ Objek II } & \multicolumn{2}{|c|}{ Objek III } \\
\cline { 3 - 8 } & & f & $\%$ & f & $\%$ & f & $\%$ \\
\hline 3 & Besar & 4 & 80.0 & 4 & 80.0 & 5 & 100.0 \\
\hline 2 & Tetap & 1 & 20.0 & 1 & 20.0 & 0 & 0.0 \\
\hline 1 & Kecil & 0 & 0.0 & 0 & 0.0 & 0 & 0.0 \\
\hline & Jumlah & 5 & 100.0 & 5 & $\begin{array}{c}100 . \\
0\end{array}$ & 5 & 100.0 \\
\hline
\end{tabular}

Tabel 7 menunjukkan bahwa distribusi frekuensi ukuran mata pada penggunaan tiga bulu mata (X2) untuk tata rias pengantin bridal dari penilaian 5 panelis terhadap objek 1 dan 2 didapatkan sebanyak 4 orang $(80.0 \%)$ panelis menilai objek pada kategori besar dan sebanyak 1 orang $(20.0 \%)$ panelis menilai pada kategori tetap. Terhadap objek 3 didapatkan sebanyak 5 orang $(100.0 \%)$ panelis menilai pada kategori besar.

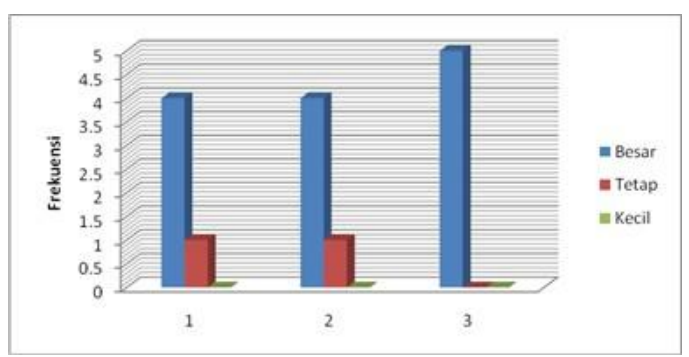

Gambar 6. Histogram Distribusi Frekuensi Ukuran Mata Pada Penggunaan tiga Bulu Mata Untuk Tata Rias Pengantin Bridal.

3. Uji Persyaratan Analisis

1. Uji Normalitas

Tabel 8 Uji Normalitas Pada Kelompok Penggunaan dua Bulu Mata Dengan Penambahan Scotch Tape Untuk Tata Rias Pengantin Bridal

\begin{tabular}{|c|l|c|c|c|}
\hline No. & \multicolumn{1}{|c|}{ Variabel } & Signifikan & Alpha & Keterangan \\
\hline 1. & Kerapian & 0.766 & 0.05 & Normal \\
\hline 2. & Kesan Mata Terlihat & 0.991 & 0.05 & Normal \\
\hline 3. & Ukuran Mata & 0.997 & 0.05 & Normal \\
\hline
\end{tabular}

Berdasarkan uraian di atas didapatkan semua uji mempunyai nilai $\mathrm{p}>0,05$, hal ini menunjukkan data berdistribusi normal.

Tabel 9. Uji Normalitas Pada Kelompok Pada Penggunaan tiga Bulu Mata Untuk Tata Rias Pengantin Bridal 


\begin{tabular}{|c|l|c|c|c|}
\hline No. & \multicolumn{1}{|c|}{ Variabel } & Signifikan & Alpha & Keterangan \\
\hline 1. & Kerapian & 1.000 & 0.05 & Normal \\
\hline 2. & Kesan Mata Terlihat & 0.766 & 0.05 & Normal \\
\hline 3. & Ukuran Mata & 0.441 & 0.05 & Normal \\
\hline
\end{tabular}

$d^{3 .}$ Uji Homogenitas

i Tabel 10 Uji Homogenitas Pada Kedua Kelompok

e

$\mathrm{m}$

$\mathrm{u}$

$\mathrm{k}$

a

\begin{tabular}{|c|l|c|c|c|}
\hline No. & \multicolumn{1}{|c|}{ Variabel } & Signifikan & Alpha & Keterangan \\
\hline 1. & Kerapian & 0.275 & 0.05 & Homogen \\
\hline 2. & Kesan Mata Terlihat & 0.275 & 0.05 & Homogen \\
\hline 3 & Ukuran Mata & 0.275 & 0.05 & Homogen \\
\hline
\end{tabular}

Berdasarkan uraian di atas didapatkan semua uji mempunyai nilai $\mathrm{p}>0,05$, hal ini menunjukkan data homogen.

a4. Pengujian Hipotesis

\section{i Tabel 10. Hasil Analisis Data Uji t}

\begin{tabular}{|c|c|c|c|c|c|}
\hline $\begin{array}{l}\text { Indikator } \\
\text { Penilaian }\end{array}$ & Hasil Ukur & Mean & SD & $\mathrm{N}$ & $\begin{array}{c}p \\
\text { value }\end{array}$ \\
\hline \multirow[t]{2}{*}{ Kerapian } & $\begin{array}{l}\text { Penggunaan dua Bulu } \\
\text { Mata Dengan } \\
\text { Penambahan Scotch Tape } \\
\text { (X1) }\end{array}$ & 1.86 & 0.462 & \multirow[t]{2}{*}{3} & \multirow[t]{2}{*}{0.035} \\
\hline & $\begin{array}{l}\text { Penggunaan tiga Bulu } \\
\text { Mata (X 2) }\end{array}$ & 2.47 & 0.503 & & \\
\hline \multirow[t]{2}{*}{$\begin{array}{l}\text { Kesan Mata } \\
\text { terlihat }\end{array}$} & $\begin{array}{l}\text { Penggunaan dua Bulu } \\
\text { Mata Dengan } \\
\text { Penambahan Scotch Tape } \\
\text { (X1) }\end{array}$ & 2.33 & 0.611 & \multirow[t]{2}{*}{3} & \multirow[t]{2}{*}{0.370} \\
\hline & $\begin{array}{l}\text { Penggunaan tiga Bulu } \\
\text { Mata (X 2) }\end{array}$ & 2.67 & 0.115 & & \\
\hline \multirow[t]{2}{*}{ Ukuran Mata } & $\begin{array}{l}\text { Penggunaan dua Bulu } \\
\text { Mata Dengan } \\
\text { Penambahan Scotch Tape } \\
\text { (X1) }\end{array}$ & 1.60 & 0.200 & \multirow[t]{2}{*}{3} & \multirow[t]{2}{*}{0.010} \\
\hline & $\begin{array}{l}\text { Penggunaan tiga Bulu } \\
\text { Mata (X 2) }\end{array}$ & 2.93 & 0.115 & & \\
\hline
\end{tabular}

Berdasarkan tabel diatas didapatkan bahwa pada indikator kerapian didapatkan nilai $\mathrm{p}<0.05(\mathrm{p}=0.035)$. Artinya terdapat perbedaan rata - rata yang signifikan antara pada kedua kelompok perlakuan. Dimana ditemukan niai rata rata tertinggi didapatkan pada kelompok penggunaan tiga Bulu Mata (X2) yaitu sebesar 2.47.

Pada indikator kesan mata terlihat didapatkan nilai $\mathrm{p}>0.05(\mathrm{p}=0.370)$. Artinya tidak terdapat perbedaan rata - rata yang signifikan antara pada kedua kelompok perlakuan. Namun ditemukan nilai rata rata tertinggi didapatkan pada kelompok penggunaan tiga Bulu Mata (X2) yaitu sebesar 2.67.

Pada indikator ukuran mata didapatkan nilai $\mathrm{p}<0.05(\mathrm{p}=0.010)$. Artinya terdapat

$\mathrm{n}$ perbedaan rata - rata yang signifikan antara

Berdasarkan uraian di atas didapatkan semua uji pada semua indikator mempunyai nilai $\mathrm{p}>0,05$, hal ini menunjukkan data berdistribusi normal.

\section{B. PEMBAHASAN}

1. Koreksi Mata Sipit Menggunakan Dua Bulu Mata Ditambah Dengan Penggunaan Scotch 
Tape Pada Rias Pengantin Bridal

Berdasarkan analisis data yang telah dikemukakan berhubungan dengan hasil penelitian terhadap sampel wanita bermata sipit dengan pemakaian dua bulu mata ditambah dengan scotch tape yang berjumlah 3 orang, dinyatakan hasil penilaian panelis pada indikator kerapian hasil koreksi memperoleh skor rata-rata 1.86 dikategorikan rapi, kesan mata terlihat memperoleh skor rata-rata 2.33 dikategorikan tetap, kesan ukuran mata memperoleh skor ratarata 1.60 dikategorikan tetap. Hal ini dikarenakan pemasangan scotch tape yang membutuhkan ketelitian dan memakan waktu yang lama saat pengaplikasiannya, sedangkan saat pelaksanaan pelitian ketersedian waktu terbatas oleh panelis. Kemudian dua bulu mata yang digunakan tidak cukup untuk mengoreksi mata sipit karena jenis bulu mata yang digunakan hanya menggunakan bulu mata natural dan bulu mata bulat. Sesuai dengan kutipan dari Gusnaldi menjelaskan bahwa bulu mata natural dapat mengoreksi mata yang kecil agar terkesan segar dan terbuka, bulu mata bulat berfungsi untuk membuat kesan mata menjadi terbuka dan sangat cocok diterapkan untuk mengoresi mata yang kecil [2]. Dari penelitian yang telah dilakukan penggunaan dua bulu mata (bulu mata natural dan bulat) kurang cukup untuk mengoreksi mata sipit sehingga hasilnya kurang maksimal.

\section{Koreksi Mata Sipit Menggunakan Tiga Bulu}

Mata Pada Rias Pengantin Bridal

Berdasarkan analisis data yang telah dikemukakan berhubungan dengan hasil penelitian terhadap sampel wanita bermata sipit dengan pemakaian tiga bulu mata yang berjumlah 3 orang, dinyatakan hasil penilaian panelis pada indikator kerapian hasil koreksi memperoleh skor rata-rata 2.20 dikategorikan rapi, kesan mata terlihat memperoleh skor ratarata 2.67 dikategorikan ideal, kesan ukuran mata memperoleh skor rata-rata 2.86 dikategorikan besar. Hal ini dapat diartikan bahwa dengan pemasangan tiga bulu mata palsu dapat memberikan hasil yang rapi, mata terkesan ideal dan kesan ukuran mata terlihat besar dari sebelumnya karena menggunakan jenis bulu mata natural, bulat dan panjang. Sesuai dengan kutipan dariGusnaldi menjelaskan bahwa untuk menyempurnakan riasan mata, penata rias perlu memperhatikan bentuk bentuk bulu mata palsu sesuai kegunaannya, selain memperhatikan ukuran yang akan digunakan [2]. Dimana bulu mata natural dapat mengoreksi mata yang kecil agar terkesan segar dan terbuka, bulu mata bulat berfungsi untuk membuat kesan mata menjadi terbuka dan sangat cocok diterapkan untuk mengoresi mata yang kecil dan bulu mata panjang mempunyai manfaat yang samadengan bulu mata tebal pinggir, sangat cocok untuk mengoreksi mata yang kecil dan sudutnya turun.

3. Perbandingan Hasil Koreksi Mata Sipit Menggunakan Dua Bulu Mata Ditambah Dengan Penambahan Scotch Tape Dan Tiga Bulu Mata Palsu Untuk Rias Pengantin Bridal

a. Perbandingan Kerapian hasil koreksi

Hasil penelitian pada kerapian hasil koreksi menunjukkan bahwa terdapat perbedaan hasil koreksi mata sipit menggunakan dua bulu mata ditambah dengan scotch tape untuk tata rias pengantin bridal (X1) dan hasil koreksi mata sipit menggunakan tiga bulu mata untuk tata rias pengantin bridal (X2), berdasarkan data yang menyatakan bahwa pada indikator kerapian didapatkan nilai $\mathrm{p}<0.05$ $(\mathrm{p}=0.035)$. Artinya terdapat perbedaan rata rata yang signifikan antara pada kedua kelompok perlakuan. Dimana ditemukan niai rata rata tertinggi didapatkan pada kelompok penggunaan tiga Bulu Mata (X2) yaitu sebesar 2.47. Diketahui bahwa rata-rata hasil penelitian yang telah dilakukan dengan dua kelompok sampel perlakuan 3 orang sampel bermata sipit dengan menggunakan dua bulu mata ditambah dengan scotch tape (X1) dan tiga bulu mata (X2) untuk rias pengantin bridal, menunjukkan bahwa keduanya memiliki tingkat kerapian hasil koreksi yang berbeda, dan diketahui bahwa kerapian hasil koreksi pada pemasangan dua bulu mata ditambah dengan scotch tape pada kelompok eksperimen 1 (X1) lebih rendah dari pemasangan tiga bulu mata pada kelompok eksperimen 2 (X2). Dengan 
demikian kedua perlakuan memiliki hasil yang berbeda secara signifikan.

b. Perbandingan Kesan mata terlihat

Hasil penelitian pada kesan mata terlihat didapatkan nilai $\mathrm{p}>0.05(\mathrm{p}=0.370)$. Artinya tidak terdapat perbedaan rata - rata yang signifikan antara pada kedua kelompok perlakuan. Namun ditemukan nilai rata rata tertinggi didapatkan pada kelompok penggunaan tiga Bulu Mata (X2) yaitu sebesar 2.67. Diketahui bahwa rata-rata hasil penelitian yang telah dilakukan dengan dua kelompok sampel perlakuan 3 orang sampel bermata sipit dengan menggunakan dua bulu mata ditambah dengan scotch tape (X1) dan tiga bulu mata (X2) untuk rias pengantin bridal, menunjukkan bahwa keduanya memiliki tingkat kesan mata terlihat yang berbeda, dan diketahui bahwa kesan mata terlihat pada pemasangan dua bulu mata ditambah dengan scotch tape pada kelompok eksperimen 1 (X1) lebih rendah dari pemasangan tiga bulu mata pada kelompok eksperimen 2 (X2). Dengan demikian kedua perlakuan memiliki hasil yang berbeda secara signifikan.

c. Perbandingan Kesan ukuran mata

Hasil penelitian pada kesan ukuran mata menunjukkan pada indikator kesan ukuran mata didapatkan nilai $\mathrm{p}<$

$0.05(\mathrm{p}=0.010)$. Artinya terdapat perbedaan rata - rata yang signifikan antara kedua kelompok perlakuan, Dimana ditemukan niai rata rata tertinggi didapatkan pada kelompok penggunaan tiga Bulu Mata (X2) yaitu sebesar 2.93. Diketahui bahwa rata-rata hasil penelitian yang telah dilakukan dengan dua kelompok sampel perlakuan 3 orang sampel bermata sipit dengan menggunakan dua bulu mata ditambah dengan scotch tape (X1) dan tiga bulu mata (X2) untuk tata rias pengantin bridal, menunjukkan bahwa keduanya memiliki tingkat kesan mata terlihat yang berbeda, dan diketahui bahwa kesan mata terlihat pada pemasangan dua bulu mata ditambah dengan scotch tape pada kelompok eksperimen 1 (X1) dan pada pemasangan tiga bulu mata pada kelompok eksperimen 2 (X2) terdapat nilai yang lebih tinggi. Dengan demikian kedua perlakuan memiliki hasil yang berbeda secara signifikan.

\section{PENUTUP}

Simpulan

Berdasarkan hasil penelitian maka dapat disimpulkan sebagai berikut, yaitu: Terdapat perbedaan tingkat kerapian pada teknik penggunaan dua bulu mata dengan penambahan scotch tape dan penggunaan tiga bulu mata untuk rias pengantin bridal $(\mathrm{p}=0,035)$. Dimana ditemukan niai rata rata tertinggi didapatkan pada kelompok penggunaan tiga Bulu Mata (X2) yaitu sebesar 2.47.

Tidak terdapat perbedaan signifikan pada indikator kesan mata terlihat pada teknik penggunaan dua bulu mata dengan penambahan scotch tape dan penggunaan tiga bulu mata untuk tata rias pengantin bridal $(\mathrm{p}=0,035)$. Namun ditemukan niai rata rata tertinggi didapatkan pada kelompok penggunaan tiga Bulu Mata (X2) yaitu sebesar 2.67.

Terdapat perbedaan signifikan pada indikator kesan mata pada teknik penggunaan dua bulu mata dengan penambahan scotch tape dan penggunaan tiga bulu mata untuk tata rias pengantin bridal $(\mathrm{p}=0,010)$. Dimana ditemukan niai rata rata tertinggi didapatkan pada kelompok penggunaan tiga Bulu Mata (X2) yaitu sebesar 2.93.

Pada penelitian ini ditemukan penggunaan tiga bulu mata palsu adalah menghasilkan kerapian, kesan mata terlihat dan ukuran mata yang lebih baik pada hasil koreksi mata sipit untuk tata rias pengantin bridal. Maka peneliti menyarankan kepada tenaga rias menggunakan teknik penggunaan tiga bulu mata palsu pada riasan mata sipit sehingga mata terlihat lebih ideal.

\section{Saran}

Hasil penelitian ini dapat menambah konsep dan teori yang selanjutnya berguna sebagai dasar dalam mengembangkan keilmuan di bidang tata rias dan kecantikan.

Pada penelitian ini ditemukan penggunaan tiga bulu mata palsu menghasilkan kerapian, kesan mata terlihat dan ukuran mata yang lebih baik pada hasil koreksi mata sipit untuk rias pengantin bridal. Maka peneliti menyarankan kepada penata rias menggunakan teknik penggunaan tiga bulu mata palsu pada riasan mata sipit sehingga mata terlihat lebih ideal.

\section{DAFTAR PUSTAKA}

Kustanti, Herni. 2008. Tata kecantikan kulit untuk SMK jilid 3. Jakarta: Direktorat Pembinaan Sekolah Menengah Kejuruan. 
Gusnaldi. 2008. I Do Bridal Make-Up. Jakarta : Gramedia Pustaka Utama.

Gusnaldi. 2010. Love Eyes Gusnaldi. Jakarta : PT.

Gramedia Pustaka Utama.

Chenny Han. 2010 . Make Up Mata Sesuai Aura dan Feng Shui. Jakarta : PT.Gramedia Pustaka Utama.

Liza, Fitry. 2017. For Your Eyes Only. Jakarta : PT.

Gramedia Pustaka Utama

Andiyanto. 2005. The Make Over rahasia wajah sempurna. Jakarta : PT. Gramedia Pustaka Utama.

Gusnaldi. 2009. Instan Make-Up. Jakarta : PT. Gramedia

Pustaka Utama. 